\title{
Comparison of non-invasive methods of assessing liver fibrosis in combination ART-experienced Zimbabweans
}

\begin{tabular}{|c|c|}
\hline \multicolumn{2}{|c|}{$\begin{array}{l}\text { Authors: } \\
\text { Brenda Nherera }{ }^{1,2} \\
\text { Kudakwashe Mhandire }^{1,2} \\
\text { Tinashe K. Nyazika } \\
\text { Alfred Makura }{ }^{1,3} \\
\text { Cuthbert Musarurwa }^{1} \\
\text { Prichard T. Mapondera }^{1,4} \\
\text { Babill Stray-Pedersen } \\
\text { Hilda T. Matarira }\end{array}$} \\
\hline $\begin{array}{l}\text { Affiliations: } \\
{ }^{1} \text { Department } \\
\text { Pathology, Fac } \\
\text { Medicine, Col } \\
\text { Sciences, Univ } \\
\text { Zimbabwe, Ha } \\
\text { Zimbabwe }\end{array}$ & $\begin{array}{l}f \text { Chemical } \\
\text { ulty of } \\
\text { ege of Health } \\
\text { ersity of } \\
\text { rare, }\end{array}$ \\
\hline $\begin{array}{l}{ }^{2} \text { Letten Found } \\
\text { House, Harare }\end{array}$ & $\begin{array}{l}\text { ation Research } \\
\text { Zimbabwe }\end{array}$ \\
\hline $\begin{array}{l}{ }^{3} \text { Malawi-Liver } \\
\text { Trust Clinical } \\
\text { Programme, } \\
\text { Malawi Colleg } \\
\text { Blantyre, Mal }\end{array}$ & $\begin{array}{l}\text { ool-Wellcome } \\
\text { esearch } \\
\text { niversity of } \\
\text { of Medicine, } \\
\text { wi }\end{array}$ \\
\hline $\begin{array}{l}{ }^{4} \text { Division of Cc } \\
\text { Health, Steller } \\
\text { University, Ca } \\
\text { South Africa }\end{array}$ & $\begin{array}{l}\text { mmunity } \\
\text { bosch } \\
\text { e Town, }\end{array}$ \\
\hline $\begin{array}{l}{ }^{5} \text { Division of W } \\
\text { Children, Insti } \\
\text { Medicine, Uni } \\
\text { Oslo, Norway }\end{array}$ & $\begin{array}{l}\text { men and } \\
\text { ute of Clinical } \\
\text { ersity of Oslo, }\end{array}$ \\
\hline $\begin{array}{l}\text { Correspondin } \\
\text { Brenda Nhere } \\
\text { nhererabrend }\end{array}$ & $\begin{array}{l}\text { author: } \\
\text { a, } \\
\text { @gmail.com }\end{array}$ \\
\hline $\begin{array}{l}\text { Dates: } \\
\text { Received: } 28 \\
\text { Accepted: } 05 \\
\text { Published: } 11\end{array}$ & $\begin{array}{l}\text { eb. } 2018 \\
\text { eb. } 2019 \\
\text { Apr. } 2019\end{array}$ \\
\hline 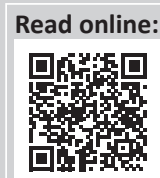 & $\begin{array}{l}\text { Scan this QR } \\
\text { code with your } \\
\text { smart phone or } \\
\text { mobile device } \\
\text { to read online. }\end{array}$ \\
\hline
\end{tabular}

Background: The prevalence of morbidity and mortality associated with liver disease among HIV-infected individuals on combination antiretroviral therapy (ART) is high. Early screening of liver disease is essential, as it provides an opportunity for successful treatment. Hence, there is a need for reliable, inexpensive and non-invasive early markers of hepatic damage.

Objectives: Non-invasive algorithms are available for assessing the extent of liver fibrosis as markers of ongoing inflammatory damage. This study compared the use of the FibroTest, Fibrosis-4 (FIB-4) index, APRI test and AST:ALT ratio in assessing liver fibrosis in combination ART-experienced individuals.

Methods: In a comparative cross-sectional study, 79 participants between the ages of 8 and 62 years were recruited. The performance of each fibrosis algorithm was determined using established cut-off scores for clinically significant liver fibrosis.

Results: The prevalence of liver fibrosis as determined by the FibroTest, FIB-4 index, APRI test and AST: ALT ratio were $19.0 \%, 21.5 \%, 12.7 \%$ and $79.7 \%$, respectively. For individual biomarkers, A-2M concentration $(p<0.001)$ and AST activity $(p=0.003)$ remained significantly elevated in participants with fibrosis than those without as defined by FibroTest and APRI test, respectively, after adjustments for multiple comparisons.

Conclusion: Our data demonstrate a high prevalence of asymptomatic liver fibrosis among combination ART-experienced individuals in Zimbabwe, and this warrants adequate monitoring of liver fibrosis in individuals on ART. Discordance of fibrosis results among the algorithms and individual biomarkers and calls for further work in identifying optimal biomarkers for detection of asymptomatic fibrosis.

Keywords: Liver fibrosis; Non-invasive methods; Biomarkers; Combination anti-retroviral therapy; Zimbabwe.

\section{Introduction}

Sub-Saharan Africa faces a substantial burden of liver disease, with mortality owing to cirrhosis doubling over the past three decades. ${ }^{1}$ Globally, liver disease accounts for $14 \%-18 \%$ of deaths among the human immunodeficiency virus (HIV)-infected population and approximately $50 \%$ of deaths among hospitalised HIV-infected individuals., ${ }^{2,3}$ Morbidity and mortality associated with liver disease in sub-Saharan Africa remains higher among the HIV-infected population than in the uninfected population despite increasing access to combination antiretroviral therapy (ART).,3,5 Longevity related to combination antiretroviral therapy among the HIV-infected population allows for the development of non-acquired immune deficiency syndrome (AIDS) events, such as nephrotoxicity, cardiovascular disease and liver complications, associated with chronic ART exposure, HIV infection itself and other comorbidities such as chronic hepatitis B virus (HBV) infection to a greater extent and hepatitis $\mathrm{C}$ virus $(\mathrm{HCV})$ infection to a lesser axtent. ${ }^{5,6}$

Whilst the liver is a regenerative organ that is capable of complete resolution with early detection and treatment, 6,7 patients with established cirrhosis or hepatocellular carcinoma (HCC) usually present late. ${ }^{1}$ Thus, timely diagnosis is critical for successful treatment, especially among HIVinfected individuals, hence the need for simple, accessible, accurate, point-of-care diagnostic technologies. ${ }^{1,6,7}$ In resource-limited settings, early detection of liver fibrosis is limited by the

How to cite this article: Nherera B, Mhandire K, Nyazika TK, et al. Comparison of non-invasive methods of assessing liver fibrosis in combination ART-experienced Zimbabweans. S Afr J HIV Med. 2019;20(1), a844. https://doi.org/10.4102/sajhivmed.v20i1.844

Copyright: @ 2019. The Authors. Licensee: AOSIS. This work is licensed under the Creative Commons Attribution License. 
unavailability of routine, non-invasive and affordable screening methods. Liver fibrosis gives rise to liver disease owing to the excessive deposition of extracellular matrix (ECM) on the hepatocytes. ${ }^{8}$ The process is gradual and not life-threatening until very late stages of the disease.

The invasive liver biopsy (LB) is the gold standard method for assessing liver fibrosis but lacks a standard interpretation protocol. This makes interpretation of results subjective and often inaccurate. ${ }^{9,10,11}$ Furthermore, liver histology gives a limited picture of only that portion of the liver from which the biopsy is derived. In contrast, the less invasive serum or plasma biomarkers of liver function, such as enzymes, provide a preview of the entire status of the liver. ${ }^{12,13}$ Consequently, serum biomarkers are thought to offer a better alternative, as there are simple tests that are readily available, reproducible, easy to apply and, if well validated, can be effectively used to follow up and monitor patients., ${ }^{9,14}$ However, individual biomarkers of liver damage are limited predictors of hepatic fibrosis, ${ }^{15,16}$ hence mathematical models that combine routinely available individual biomarkers and patient parameters into scores have been developed to improve the sensitivity and specificity of detection of fibrosis. ${ }^{8}$ These models form algorithms such as the FibroTest, Fibrosis-4 (FIB-4) index, aspartate aminotransferase to alanine aminotransferase (AST: ALT) ratio and aspartate aminotransferase to platelet ratio index (APRI) test. ${ }^{8,17}$

FibroTest is a patented, non-invasive algorithm that has been shown to accurately predict liver fibrosis in different aetiologies of liver disease. ${ }^{10,18}$ FibroTest results have been shown to be comparable to the LB findings and have been used as an alternative diagnostic method in predicting liver fibrosis in several countries since 2002. ${ }^{19,20}$ Not so much the other algorithms despite their potential to improve access to diagnosis of liver fibrosis. Furthermore, these algorithms have not been validated in non-Caucasian populations, and their utility in African populations is sparsely reported in literature.

Transient elastography also referred to as the Fibroscan is another non-invasive, highly acceptable, rapid and painless method of assessing liver fibrosis. ${ }^{21,22}$ The technique is not serum or plasma based, but it uses both ultrasound and lowfrequency elastic waves to quantify liver fibrosis. The method has been validated for liver fibrosis staging in patients with chronic liver diseases. ${ }^{21}$ The method is increasingly used in Europe; however, there are limited data on its utility in African populations. ${ }^{22}$ The present study aimed to determine the prevalence of significant liver fibrosis in ART-experienced individuals using four serum-based algorithms and comparing their performance.

\section{Materials and methods Study participants and sample collection}

Between June and September 2014, we prospectively recruited 79 consecutive individuals from Harare Central Hospital and Parirenyatwa Group of Hospitals Opportunistic
Infections Clinic, Harare, Zimbabwe. All our participants were HIV-infected and on ART for at least six months. Nonambulatory patients, tuberculosis co-infected patients and pregnant women were excluded from the study. On enrolment, a questionnaire was administered to obtain medico-demographic data from each participant. Five millilitres $(\mathrm{mL})$ of blood were collected from each participant into plain tubes and samples were centrifuged and had serum aliquoted within $2 \mathrm{~h}$ of bleeding.

One aliquot of serum was immediately analysed for ALT, AST, g-glutamyl transferase (GGT), total bilirubin (TBil) and HBV, whilst another aliquot was immediately frozen and kept at $-80{ }^{\circ} \mathrm{C}$ for six weeks before measurement of haptoglobin, apolipoprotein A-1 (Apo A-1) and alpha-2 macroglobulin (A-2M) concentrations. Another $5 \mathrm{~mL}$ of blood were collected in ethylenediaminetetraacetic acid (EDTA) tubes and analysed for platelet count within $3 \mathrm{~h}$ of phlebotomy.

\section{Laboratory analysis}

Platelet count was determined using a Sysmex XT-4000i automated Hematology analyser (Sysmex Corporation, Kobe, Japan). Haptoglobin, Apo A-1 and A-2M concentrations were determined using the sandwich enzymelinked immunosorbent assay (ELISA) method (Elabscience Biotechnology Co., Ltd, Wuhan, China). The serum activities of ALT, AST, GGT and TBil concentration were determined using the Beckman Coulter AU680 Chemistry analyser (Beckman Coulter, Inc., Mishima, Japan). Hepatitis B virus status was determined using the Hightop one step rapid HBV (5-in-1) test kit (Qingdao Hightop Biotech Co., Ltd, Shandong, China). All assays were performed following the manufacturer's instructions.

\section{Algorithms for detection of fibrosis}

The specific formulae used to determine the algorithm scores are shown in Table 1.

\section{Statistical analysis}

The Mann-Whitney test was used to compare non-parametric continuous variables between participants with significant fibrosis and those without. Kappa test was used to assess degree of agreement between algorithms. Cut-off values for significant hepatic fibrosis were as follows: APRI test $>0.5$, FIB-4 index $\geq 1.45$, FibroTest $\geq 0.32$ and AST:ALT ratio $>1$.

TABLE 1: Formulae of non-invasive algorithms for detection of fibrosis used in the study.

\begin{tabular}{|c|c|}
\hline Formula & Equation \\
\hline FibroTest & $\begin{array}{l}4.467 \times \log [\mathrm{A}-2 \mathrm{M}(\mathrm{g} / \mathrm{L})]-1.357 \times \log [\text { Haptoglobin }(\mathrm{g} / \mathrm{L})]+1.017 \times \\
\log [\mathrm{GGT}(\mathrm{IU} / \mathrm{L})]+0.0281 \times[\text { Age }(\text { years })]+1.737 \times \log [\mathrm{TBil} \\
(\mu \mathrm{mol} / \mathrm{L})]-1.184 \times[\text { Apo A-1 }(\mathrm{g} / \mathrm{L})]+0.301 \times \mathrm{Gender} \\
(\text { Female }=0, \text { Male }=1)-5.540(\text { www.biopredictive.com })\end{array}$ \\
\hline FIB-4 index & [Age $($ years $) \times$ AST $($ IU $/$ L) $] /\left[\right.$ Platelets $\left(\times 10^{9} /\right.$ L) $\times$ VALT $\left.(I U / L)\right]$ \\
\hline APRI test & [(AST (IU/L)/ ULN)/Platelet count $\left.\left(\times 10^{9} / \mathrm{L}\right)\right] \times 100$ \\
\hline AST: ALT ratio & AST/ALT \\
\hline
\end{tabular}

ULN, upper limit of normal, ULN of AST: 42 IU/L (according to the local laboratory standards); APRI, aminotransferase to platelet ratio index; FIB-4, Fibrosis-4 index; AST, aspartate aminotransferase; ALT, alanine aminotransferase. 
These values have been reported to be predictive of significant hepatic fibrosis and were adopted for this study. ${ }^{10,23,24,25}$ All statistical analyses were performed using Stata 13.0 (Stata Corp., College Station, Texas, USA) software package and a $p$-value of $<0.05$ was considered statistically significant.

\section{Ethical consideration}

The study protocol was approved by the Joint Parirenyatwa Hospital and College of Health Sciences Research Ethics Committee (JREC Ref: 45/14). All participants gave written informed patient consent or assent. Consent was granted by parents or guardians in the case of minors.

\section{Results}

\section{Characteristics of the study population}

We enrolled 79 HIV-infected individuals with mean age and standard deviation (s.d.) of 41 and 11 years, respectively. The majority of participants $(65.8 \% ; n=55)$ were female and the average body mass index (BMI) was $23 \mathrm{~kg} / \mathrm{m}^{2}$, with $14.7 \%$ being underweight, $61.8 \%$ being normal weight, $14.7 \%$ being overweight and $8.8 \%$ being obese. Seventy-six per cent of the participants were on nucleoside reverse transcriptase inhibitor (NRTI) plus non-nucleoside reverse transcriptase inhibitors (NNRTI), 17.7\% were taking NRTIs plus protease inhibitor (PI) whilst $6.3 \%$ were taking NRTIs only. The duration on ART ranged from 1 to 13 years with a median of four years and six months and interquartile range (IQR) of 2-7 years. Based on serological tests, 3.8\% $(n=3)$ of study participants had HIV/HBV co-infection. The demographic characteristics of the study participants are shown in Table 2.

\section{Utility of algorithms for the prediction of hepatic fibrosis}

We first determined the prevalence of fibrosis in our study participants using each of the four algorithms (FibroTest, FIB-4 index, APRI test and AST:ALT ratio). The prevalence of fibrosis according to each algorithm were: FibroTest (19\%), FIB-4 index (21.5\%), APRI test $(12.7 \%)$ and AST:ALT ratio $(79.7 \%)$, as shown in Figure 1.

The average prevalence of fibrosis was $17.7 \%$ using the three comparable algorithms (FibroTest, FIB-4 index and APRI test) but increased to $33.2 \%$ when AST:ALT ratio was included. Notably, $19.4 \%(n=7)$ of the $36 / 79(45.6 \%)$

TABLE 2: Demographic characteristics of study participants.

\begin{tabular}{lc}
\hline Parameter & Participants $(\boldsymbol{n}=\mathbf{7 9})$ \\
\hline Gender: Females $n(\%)$ & $52(65.8)$ \\
Age (years) mean \pm s.d. & $41 \pm 11$ \\
Height (metres) median (IQR) & $1.70(1.60-1.70)$ \\
Weight $(\mathrm{kg})$ median (IQR) & $66(56-75)$ \\
$\mathrm{BMI}\left(\mathrm{kg} / \mathrm{m}^{2}\right)$ mean \pm s.d. & $23 \pm 4.4$ \\
$\mathrm{CD} 4+$ count (cells/uL) median (IQR) & $416(254-624)$ \\
HIV/HBV co-infection, $n(\%)$ & $3(3.8)$ \\
Period on ART (years) median (IQR) & $4.5(2-7)$ \\
Patients taking alcohol, $n(\%)$ & $11(13.9)$ \\
\hline
\end{tabular}

s.d., standard deviation; IQR, interquartile range; BMI, body mass index; HIV/HBV, human immunodeficiency virus/hepatitis B virus; ART, antiretroviral therapy. participants receiving nevirapine-containing ART regimens had significant fibrosis based on the FibroTest, which has been validated in other settings. ${ }^{19,20}$ One of the three participants co-infected with HBV had significant fibrosis as determined by the FibroTest. When we performed the test for agreement among the non-invasive algorithms, there was a moderate agreement between FIB- 4 index and APRI test $(k=0.46)$, fair agreement between (1) FibroTest and FIB-4 index $(k=0.40)$ and $(2)$ between FibroTest and APRI test $(k=0.25)$. The AST:ALT ratio was in poor agreement with all three other algorithms: FibroTest $(k=0.08)$, FIB-4 index $(k=0.10)$ and APRI test $(k=0.08)$.

\section{Individual biomarkers in fibrosis and non- fibrosis as defined by FibroTest}

We compared individual serum biomarkers between participants with significant fibrosis and those without as defined by FibroTest. Total bilirubin and A-2M concentrations were significantly elevated in participants with fibrosis, median (IQR) $7 \mu \mathrm{mol} / \mathrm{L}$ (5-46) versus 5 $\mu \mathrm{mol} / \mathrm{L}(4-7)(p=0.029)$ and $1.5 \mathrm{~g} / \mathrm{L}(1.1-2.9)$ versus $0.2 \mathrm{~g} / \mathrm{L}$ $(0.1-0.8)(p<0.001)$, respectively, when compared to those without fibrosis. However, after adjusting for multiple comparisons with the Bonferroni adjustment, only A-2M $(p<0.001)$ remained significant. The findings are summarised in Table 3.

\section{Individual biomarkers in fibrosis and non- fibrosis defined by aspartate aminotransferase to platelet ratio index test}

We further compared individual serum biomarkers based on APRI test strata. Aspartate aminotransferase and Apo A-1 were significantly elevated in participants with fibrosis median (IQR) 50 (32-77) IU/L versus 28 (23-36) IU/L $(p=0.005)$ and $1.6(1.2-1.8) \mathrm{g} / \mathrm{L}$ versus $0.9(0.5-1.5) \mathrm{g} / \mathrm{L}$ $(p=0.027)$, respectively, when compared to those without

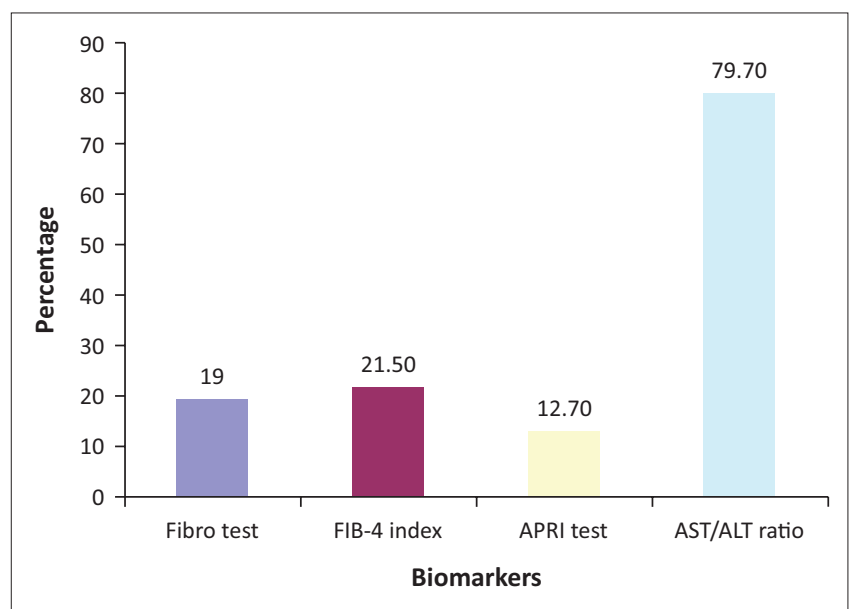

FIGURE 1: Prevalence of hepatic fibrosis as determined by non-invasive biomarkers. The figure shows the prevalence (\%) of significant liver fibrosis in antiretroviral therapy-experienced participants as determined by the noninvasive algorithms (FibroTest 19\%, Fibrosis-4 [FIB-4] index $21.5 \%$, aspartate aminotransferase to platelet ratio index [APRI] test $12.7 \%$ and aspartate aminotransferase to alanine aminotransferase [AST:ALT] ratio $79.7 \%$ ). 
TABLE 3: Comparison of biomarkers in participants with significant fibrosis and those without as defined by the FibroTest.

\begin{tabular}{|c|c|c|c|c|c|}
\hline \multirow[t]{2}{*}{ Variable } & \multicolumn{2}{|c|}{$\begin{array}{l}\text { Participants with } \\
\text { no fibrosis }(n=63)\end{array}$} & \multicolumn{2}{|c|}{$\begin{array}{l}\text { Participants with } \\
\text { fibrosis }(n=16)\end{array}$} & \multirow[t]{2}{*}{$p$} \\
\hline & Median & IQR & Median & IQR & \\
\hline AST (IU/L) & 28 & $24-37$ & 33 & $27-39$ & 0.366 \\
\hline ALT (IU/L) & 24 & $16-36$ & 22 & $16-31$ & 0.696 \\
\hline GGT (IU/L) & 39 & $25-59$ & 51 & $29-75$ & 0.566 \\
\hline TBil $(\mu \mathrm{mol} / \mathrm{L})$ & 5 & $4-7$ & 7 & $5-46$ & $\begin{array}{l}0.029 \\
0.203 *\end{array}$ \\
\hline Apo A-1 (g/L) & 0.94 & $0.53-1.58$ & 1.38 & $0.47-1.66$ & 0.579 \\
\hline Haptoglobin (g/L) & 0.037 & $0.012-0.064$ & 0.019 & $0.003-0.065$ & 0.542 \\
\hline $\mathrm{A}-2 \mathrm{M}(\mathrm{g} / \mathrm{L})$ & 0.196 & $0.092-0.811$ & 1.501 & $1.065-2.893$ & $\begin{array}{l}<0.001 \\
<0.001 *\end{array}$ \\
\hline \multicolumn{6}{|c|}{$\begin{array}{l}\text { TBil, total bilirubin; GGT, g-glutamyl transferase; AST, aspartate aminotransferase; ALT, } \\
\text { alanine aminotransferase; Apo A-1, apolipoprotein A-1; A-2M, alpha-2 macroglobulin; IQR, } \\
\text { interquartile range; IU/L. }\end{array}$} \\
\hline \multicolumn{6}{|c|}{$\begin{array}{l}\text { For all statistical analyses and bold } p \text {-values in tables, significance was set at } 0.05 \text {. } \\
* \text {, Bonferroni adjusted } p \text {-value. }\end{array}$} \\
\hline
\end{tabular}

TABLE 4: Comparison of biomarkers in participants with significant fibrosis and those without as defined by the aspartate aminotransferase to platelet ratio index test.

\begin{tabular}{|c|c|c|c|c|c|}
\hline \multirow[t]{2}{*}{ Variable } & \multicolumn{2}{|c|}{$\begin{array}{l}\text { Participants with } \\
\text { no fibrosis }(n=68)\end{array}$} & \multicolumn{2}{|c|}{$\begin{array}{l}\text { Participants with } \\
\text { fibrosis }(n=11)\end{array}$} & \multirow[t]{2}{*}{$p$} \\
\hline & Median & IQR & Median & IQR & \\
\hline AST (IU/L) & 28 & $23-36$ & 50 & $32-77$ & $\begin{array}{l}0.005 \\
0.003^{*}\end{array}$ \\
\hline ALT (IU/L) & 22 & $16-32$ & 31 & $19-73$ & 0.151 \\
\hline GGT (IU/L) & 38 & $25-61$ & 53 & $36-102$ & 0.266 \\
\hline TBil (umol/L) & 5 & $4-7$ & 4 & $4-7$ & 0.371 \\
\hline Apo A-1 (g/L) & 0.926 & $0.477-1.521$ & 1.585 & $1.215-1.814$ & $\begin{array}{l}0.027 \\
0.186 *\end{array}$ \\
\hline Haptoglobin (g/L) & 0.037 & $0.008-0.059$ & 0.039 & $0.013-0.101$ & 0.681 \\
\hline $\mathrm{A}-2 \mathrm{M}(\mathrm{g} / \mathrm{L})$ & 0.310 & $0.114-0.974$ & 0.663 & $0.097-1.430$ & 0.723 \\
\hline
\end{tabular}

AST, aspartate aminotransferase; ALT, alanine aminotransferase; GGT, g-glutamyl transferase TBil, total bilirubin; Apo A-1, apolipoprotein A-1; A-2M, alpha-2 macroglobulin; IQR, interquartile range; IU/L.

For all statistical analyses and bold $p$-values in tables, significance was set at 0.05 .

*, Bonferroni adjusted $p$-value.

and after adjusting for multiple comparisons with the Bonferroni adjustment, only AST $(p=0.003)$ remained significant. Table 4 summarises these findings.

\section{Correlation between significant fibrosis and participants' characteristics}

A correlation between significant fibrosis according to FIB-4 index and patients' characteristics, which were age, gender, BMI, CD4+ cell count and period on ART, was performed. Only age correlated significantly ( $p=0.0058)$, suggesting there is an association between old age and the presence of hepatic fibrosis.

\section{Discussion}

Data on the epidemiology and prevalence of liver disease are essential for the awareness, diagnosis, management and prioritisation of public health resources. ${ }^{1}$ In this study, we observed a moderately high prevalence of asymptomatic liver fibrosis $(12.7 \%-21.5 \%)$ based on FibroTest, APRI test and FIB-4 index. This, to our knowledge, is the first data from a Zimbabwean population to demonstrate liver fibrosis in ART-experienced patients using the algorithms. Our observed prevalence of liver fibrosis was higher when compared to other studies that have quantified the presence of hepatic fibrosis in HIV-infected individuals using different non-invasive serum algorithms.

A number of factors are said to contribute to the development of liver fibrosis in HIV-infected patients. The virus itself has been shown to cause liver fibrosis by activating hepatic stellate cells, which are the principal fibrogenic cells in the liver., 5,626 Liver fibrosis in this group of patients can be drug-induced. Some studies have shown that nevirapine-containing regimens are associated with an increased risk of liver fibrosis because nevirapine causes direct hepatic damage. ${ }^{2}$ Our study demonstrated that $19.4 \%$ of the $45.6 \%$ of participants receiving nevirapine-containing regiments had significant fibrosis. Other risk factors associated with the development of fibrosis in this group of patients include cardiovascular diseases, diabetes mellitus, dyslipidaemias, being obese and ageing. ${ }^{26}$

Human immunodeficiency virus-positive individuals usually present with thrombocytopenia ${ }^{27}$ and the APRI test makes use of platelet count in its formula; this in turn falsely increases the prevalence of significant fibrosis as determined by the APRI test. In a Kenyan study, the APRI test was performed on HIV-monoinfected patients and they obtained a prevalence of $8.6 \%$; a study done in the US obtained a prevalence of $8.3 \%$ and another study called the Strategic Timing of AntiRetroviral Treatment (START) trial with a heterogeneous population of Asians, Europeans and Australians obtained a prevalence of $8.5 \%{ }^{6,28,29}$ These prevalences were all lower than the $12.7 \%$ that we obtained in this study. The US study used a cut-off of $>1.5$, whilst our study, the Kenyan study, and the START trial used a cut-off of $>0.5$, and this could have lowered the prevalence of fibrosis in the US study.

A Moroccan study that performed the FIB-4 index on HIVmonoinfected participants observed a prevalence of $15.5 \%$, which was higher than the $10 \%$ obtained by the START trial. ${ }^{6,30}$ Our study found a prevalence of $21.5 \%$, which was higher than the prevalence in both Morocco and the START trial. Our mean age was higher (41 years) compared to the Moroccan (39.8 years) and the START trial (35 years), which could have consequently increased our prevalence as the FIB4 index incorporates age in its formula and age, has been found to be a risk factor for development of fibrosis. ${ }^{28,31}$

The kappa analysis we performed demonstrated that the FIB-4 index, APRI test and FibroTest performed comparably. Concordance between FIB4-index and FibroTest has been reported elsewhere in a study conducted on individuals with $\mathrm{HCV}$ monoinfection $(k=0.561) .{ }^{25} \mathrm{~A}$ moderate agreement between the APRI test and FIB-4 index has also been shown in an HIV monoinfection population $(k=0.573)^{32}$ and in an HCV monoinfection population $(k=0.507),{ }^{33}$ and these results are comparable to the $k=0.46$ that we observed in our study. Another study compared the APRI test and the FIB- 4 index to the LB in patients with non-alcoholic fatty liver disease and obtained a fair and statistically significant agreement, APRI test $(k=0.33)$ and FIB-4 index $(k=0.34){ }^{34}$ These results further confirm that the two tests are comparable in different liver fibrosis aetiologies and even against the LB, which is the gold 
standard test. In contrast, AST:ALT ratio performance was not comparable to any of the other three algorithms, showing poor agreement with any of the three algorithms. Therefore, we speculate that this discordance could be owing to overexpression of AST from non-hepatic sources and also delayed clearance of AST relative to ALT. ${ }^{35,36}$ Thus, making AST-based algorithms problematic in assessing liver fibrosis by overestimating the degree of liver fibrosis. AST:ALT ratio consequently becomes a very unreliable test for estimating significant fibrosis in ARTexperienced individuals. Among the comparable algorithms, FIB-4 index is the best in terms of reliability and ease of performing because it includes age in its calculations and the tests involved in calculation are routinely available.

We compared individual biomarkers between fibrotic and non-fibrotic individuals as defined by the FibroTest and APRI test to determine the possible utility of using a single biomarker in prediction of fibrosis. Only AST and A2M remained significantly higher in patients with liver fibrosis compared to those without, adjusting for multiple comparisons. We therefore speculate that the observed significance could be because of the fact that (1) most of the AST in hepatocytes is located in the mitochondria and damage to hepatocytes causes the release of both the cytoplasmic and mitochondrial AST, leading to a raised AST in liver fibrosis, ${ }^{35}$ and (2) alpha-2 macroglobulin, a PI, is produced by hepatocytes, granuloma cells and hepatic stellate cells during inflammation. Hence, its synthesis is increased as the body tries to inhibit breakdown of ECM proteins, which favours fibrosis. ${ }^{37}$ In our study, A-2M was able to strongly distinguish fibrosis from non-fibrosis and this has also been demonstrated in a study conducted in Romania. ${ }^{37}$ Aspartate aminotransferase significantly distinguished fibrosis from non-fibrosis, but the enzyme is not a good individual biomarker of liver fibrosis as it is not solely produced by the liver and this results in false-positives. On the contrary, A-2M is an excellent individual biomarker of liver fibrosis, but analysis of this protein is costly, thus making it not ideal for routine assessment of liver fibrosis in poor resource settings.

This study was limited by the unavailability of liver LB, which is the gold standard method for assessing liver fibrosis. We could not assay LB on our patients as it is ethically unacceptable for routine monitoring of liver fibrosis, particularly in the HIV-infected individuals because it increases the risks of coagulopathies. ${ }^{8,35,38}$ However, including LB in our study could have potentially helped us in drawing a stronger conclusion on the diagnostic performance of each algorithm. Transient elastography was going to be a better comparator among the non-invasive tools of assessing liver fibrosis. However, the test was not performed owing to a lack of availability of the test and also budget constraints. Cut-off values used in our study were based on studies performed mainly in Europe, with most participants having HCV. ${ }^{18,39}$ Although we have no reason to believe that the cut-off values would differ in our setting, studies to validate the cut-off values in an African population are recommended.
In conclusion, this is the first study in Zimbabwe to demonstrate that algorithms such as FIB4-index, APRI test and FibroTest together with individual serum biomarkers like A-2M can be used as alternative methods for assessing liver fibrosis in asymptomatic, HIV-infected individuals on ART. The moderately high prevalence of asymptomatic liver fibrosis obtained in this study warrants adequate monitoring among ART-experienced individuals. The discordance of fibrosis results among the algorithms, and individual biomarkers call for further work in identifying optimal biomarkers for detection of asymptomatic fibrosis. However, AST:ALT ratio does not require further work, as it has been shown to be an unreliable test for assessing liver fibrosis. Whilst a number of studies, including the Ugandan study, ${ }^{16}$ have demonstrated high levels of fibrosis in HIVmonoinfected patients, the natural history and long-term liver outcomes in this group of patients have not been well described. There is, therefore, an urgent need to have welldesigned cohort studies looking at long-term outcomes in this group of patients and an easy to apply non-invasive test in this setting. Introducing better non-invasive markers of liver fibrosis in Zimbabwe and sub-Saharan Africa has a potential of simplifying and improving the way ARTexperienced patients are monitored for liver fibrosis.

\section{Acknowledgements}

The authors would like to thank the Letten foundation for funding this project and all the participants for participating in this study. The authors extend their gratitude to the personnel of the Department of Chemical Pathology, College of Health Sciences, University of Zimbabwe for all the support throughout the whole project.

\section{Competing interests}

The authors declare that they have no financial or personal relationship(s) which may have inappropriately influenced them in writing this article.

\section{Authors' contributions}

B.N., K.M., Prof. B.S.-P. and Prof. H.T.M. conceived the study and its design. B.N., A.M. and T.K.N. participated in the collection of clinical material and study participant recruitment. B.N., A.M. and C.M. conducted laboratory tests. B.N., P.T.M. and K.M. performed data analysis. B.N. wrote the first draft with inputs from K.M., T.K., A.M., C.M., P.T.M., Prof. H.T.M. and Prof. B.S.-P. All authors reviewed and approved the final version of the manuscript.

\section{References}

1. Spearman CW, Sonderup MW. Health disparities in liver disease in sub-Saharan Africa. Liver Int. 2015;35(9):2063-2071. https://doi.org/10.1111/liv.12884

2. Price JC, Thio CL. Liver disease in the HIV-coinfected individual. Clin Gastroenterol Hepatol. 2010;8(12):1002-1012. https://doi.org/10.1016/j.cgh.2010.08.024

3. Weber R, Sabin CA, Friis-Møller N, et al. Liver-related deaths in persons infected with the Human Immunodeficiency Virus: The D: A: D study. Arch Intern Med. 2006;166(15):1632-1641. https://doi.org/10.1001/archinte.166.15.1632 
4. Palella FJ, Jr, Baker RK, Moorman AC, et al. Mortality in the highly active antiretroviral therapy era: Changing causes of death and disease in the HIV outpatient study. J Acquir Immune Defic Syndr. 2006:43(1):27-34. https://doi. outpatient study. J Acquir Immune Defic
org/10.1097/01.qai.0000233310.90484.16

5. Iroezindu MO, Agbaji OO, Daniyam CA, Isiguzo GC, Isichei C, Akanbi MO. Liver function test abnormalities in Nigerian patients with Human Immunodeficiency Virus and hepatitis B virus co-infection. Int J STD AIDS. 2013:24(6):461-467. Virus and hepatitis B virus co-infection. Int
https://doi.org/10.1177/0956462412473889

6. Matthews GV, Neuhaus J, Bhagani S, et al. Baseline prevalence and predictors of liver fibrosis among HIV-positive individuals: A substudy of the INSIGHT Strategic Timing of AntiRetroviral Treatment (START) trial. HIV Med. 2015;16(S1):129-136. https://doi.org/10.1111/hiv.12241

7. Bataller RN, Brenner DA. Liver fibrosis. J Clin Invest. 2005;115(2):209-218. https:// doi.org/10.1172/JCI24282

8. Baranova A, Lal P, Birerdinc A, Younossi ZM. Non-invasive markers for hepatic fibrosis BMC Gastroenterol. 2011;11(1):91. https://doi.org/10.1186/1471-230X-11-91

9. Castera L. Noninvasive methods to assess liver disease in patients with hepatitis B or C. Gastroenterology. 2012;142(6):1293-1302. https://doi.org/10.1053/j.gastro. 2012.02.017

10. Liu T, Wang X, Karsdal MA, Leeming DJ, Genovese F. Molecular serum markers of liver fibrosis. Biomark Insights. 2012;7:105-117. https://doi.org/10.4137/BMI. S10009

11. Sebastiani G, Vario A, Guido M, Alberti A. Sequential algorithms combining noninvasive markers and biopsy for the assessment of liver fibrosis in chronic hepatitis B. World J Gastroenterol. 2007;13(4):525-531. https://doi.org/10.3748/wjg.v13. i4.525

12. Gressner OA, Weiskirchen R, Gressner AM. Biomarkers of liver fibrosis: Clinical translation of molecular pathogenesis or based on liver-dependent malfunction tests. Clin Chim Acta. 2007;381(2):107-113. https://doi.org/10.1016/j.cca.2007. 02.038

13. Rockey DC, Bissell DM. Noninvasive measures of liver fibrosis. Hepatology. 2006;43(S1):S113-S120. https://doi.org/10.1002/hep.21046

14. Fallatah HI. Noninvasive biomarkers of liver fibrosis: An overview. Adv Hepatol. 2014;2014.

15. Martin-Carbonero L, De Ledinghen V, Moreno A, et al. Liver fibrosis in patients with chronic hepatitis $C$ and persistently normal liver enzymes: Influence of HIV infection. J Viral Hepat. 2009;16(11):790-795. https://doi.org/10.1111/j.1365infection. J Viral Hepa

16. Staabinski L, Reynolds SJ, Ocama P, et al. High prevalence of liver fibrosis associated with HIV infection: A cross-sectional study in rural Rakai, Uganda. Antivir Ther. 2011;16(3):405-411. https://doi.org/10.3851/IMP1783

17. Amaral IdSA, Dias MPF, Fernandes CCR, Moia LdJMsP, Miranda ECBM, Demachki S. Evaluation of APRI test as a liver fibrosis marker. Rev Para Med. 2007;21(4): 7-13.

18. Poynard T, Morra R, Halfon P, et al. Meta-analyses of FibroTest diagnostic value in chronic liver disease. BMCGastroenterol. 2007;7(1):40. https://doi.org/10.1186/1471230X-7-40

19. Poynard T, Imbert-Bismut F, Munteanu M, et al. Overview of the diagnostic value of biochemical markers of liver fibrosis (FibroTest, HCV FibroSure) and necrosis (ActiTest) in patients with chronic hepatitis C. Comp Hepatol. 2004;3(1):8. https:// doi.org/10.1186/1476-5926-3-8

20. Liu S, Schwarzinger MI, Carrat F, Goldhaber-Fiebert JD. Cost effectiveness of fibrosis assessment prior to treatment for chronic hepatitis $C$ patients. PLoS One. 2011;6(12):e26783. https://doi.org/10.1371/journal.pone.0026783

21. Perazzo H, Veloso VG, Grinsztejn B, Hyde C, Castro R. Factors that could impact on liver fibrosis staging by transient elastography. Int J Hepatol. 2015;2015.
22. Kirk GD, Astemborski J, Mehta SH, et al. Assessment of liver fibrosis by transient elastography in persons with hepatitis C virus infection or HIV-hepatitis C virus coinfection. Clin Infect Dis. 2009;48(7):963-972. https://doi.org/10.1086/597350

23. Wai C, Greenson JK, Fontana RJ, et al. A simple noninvasive index can predict both significant fibrosis and cirrhosis in patients with chronic hepatitis $\mathrm{C}$. Hepatology. 2003;38(2):518-526. https://doi.org/10.1053/jhep.2003.50346

24. Ngo $Y$, Munteanu $M$, Messous $D$, et al. A prospective analysis of the prognostic value of biomarkers (FibroTest) in patients with chronic hepatitis C. Clin Chem. 2006;52(10):1887-1896. https://doi.org/10.1373/clinchem.2006.070961

25. Vallet-Pichard A, Mallet V, Nalpas B, et al. FIB-4: An inexpensive and accurate marker of fibrosis in HCV infection. comparison with liver biopsy and fibrotest. Hepatology. 2007;46(1):32-36. https://doi.org/10.1002/hep.21669

26. Rockstroh JK, Mohr R, Behrens G, Spengler U. Liver fibrosis in HIV: Which role does HIV itself, long-term drug toxicities and metabolic changes play? Curr Opin HIV AIDS. 2014;9(4):365-370. https://doi.org/10.1097/COH.0000000000000064

27. Scaradavou A. HIV-related thrombocytopenia. Blood Rev. 2002;16(1):73-76. https:// doi.org/10.1054/blre.2001.0188

28. Gitau SN, Vinayak S, Silaba M, Adam R, Shah R. High prevalence of liver fibrosis in patients with human immunodeficiency virus monoinfection and human immunodeficiency virus Hepatitis-B co-infection as assessed by shear wave elastography: Study at a teaching hospital in Kenya. J Clin Imaging Sci. 2016;6:22 elastography: Study at a teaching hospital in
https://doi.org/10.4103/2156-7514.183582

29. DallaPiazza M, Amorosa VK, Localio R, Kostman JR, Re VL. Prevalence and risk factors for significant liver fibrosis among HIV-monoinfected patients. BMC Infect Dis. 2010;10(1):116. https://doi.org/10.1186/1471-2334-10-116

30. Tahiri M, Sodqi M, Lahdami FEZ, et al. Risk factors for liver fibrosis among Human Immunodeficiency Virus monoinfected patients using the FIB4 index in Morocco. World J Hepatol. 2013;5(10):584-588. https://doi.org/10.4254/wjh.v5.i10.584

31. de Torres M, Poynard T. Risk factors for liver fibrosis progression in patients with chronic hepatitis C. Ann Hepatol. 2003;2(1):5-11.

32. Mendeni $M$, Focà $E$, Gotti $D$, et al. Evaluation of liver fibrosis: Concordance analysis between noninvasive scores (APRI and FIB-4) evolution and predictors in a cohort of HIV-infected patients without hepatitis C and B infection. Clin Infect Dis. 2011;52(9):1164-1173. https://doi.org/10.1093/cid/cir071

33. Paranaguá-Vezozzo DC, Andrade A, Mazo DF, et al. Concordance of non-invasive mechanical and serum tests for liver fibrosis evaluation in chronic hepatitis C. World J Hepatol. 2017;9(8):436-442. https://doi.org/10.4254/wjh.v9.i8.436

34. Atay K, Canbakan B, Alan O, et al. Evaluation of non-invasive diagnostic methods as indicators of fibrosis in patients with nonalcoholic fatty liver disease. Biomed Res. 2017;28(2):565-570.

35. Park GJ, Lin BP, Ngu MC, Jones DB, Katelaris PH. Aspartate aminotransferase: Alanine aminotransferase ratio in chronic hepatitis $C$ infection: Is it a useful predictor of cirrhosis? J Gastroenterol Hepatol. 2000;15(4):386-390. https://doi. predictor of cirrhosis? $\mathrm{org} / 10.1046 / \mathrm{j} .1440-1746.2000 .02172 . x$
.

36. El Nakeeb NA, Helmy A, Saleh SA, Abdellah HM, Aleem MHA, Elshennawy D. Comparison between FIB-4 Index and Fibroscan as marker of fibrosis in chronic HCV infection in Egyptian patients. Open J Gastroenterol. 2014;4(12):383-391. https://doi.org/10.4236/ojgas.2014.412052

37. Grigorescu $M$, Rusu $M$, Neculoiu $D$, et al. The FibroTest value in discriminating between insignificant and significant fibrosis in chronic hepatitis $C$ patients. The Romanian experience. J Gastrointestin Liver Dis. 2007;16(1):31-37.

38. Shaheen AA, Myers RP. Systematic review and meta-analysis of the diagnostic accuracy of fibrosis marker panels in patients with HIV/hepatitis C coinfection. HIV Clin Trials. 2008;9(1):43-51. https://doi.org/10.1310/hct0901-43

39. Rossi E, Adams L, Prins A, et al. Validation of the FibroTest biochemical markers score in assessing liver fibrosis in hepatitis C patients. Clin Chem. 2003;49(3) 450-454. https://doi.org/10.1373/49.3.450 